\title{
Determinant Factors of Interprofessional Collaborationin Labuang Baji General Hospital
}

\author{
Patima Patima ${ }^{1}$, Ridwan Amiruddin R. ${ }^{2}$, Syahrir A. Pasinring ${ }^{2}$, \\ A. Ummu Salmah ${ }^{2}$, Ariyanti Saleh ${ }^{2}$, Fridawaty Rivai ${ }^{2}$, Anwar Mallongi ${ }^{2}$ \\ ${ }^{1}$ Doctoral Program Science of Public Health, Universitas Hasanuddin, Indonesia, ${ }^{1}$ Faculty of Nursing, UIN \\ Alauddin Makassar, Indonesia, ${ }^{2}$ Faculty of Public Health, Universitas Hasanuddin, Indonesia
}

\begin{abstract}
Background: Health services provided to the community were often overlapped among health care professionals. Poor communication may affect the quality of patient care and potentially increase the number of medical errors.
\end{abstract}

Objective: The study aims to analyze the most determinant factors associated with the implementation of Interprofessional Collaboration (IPC) at Labuang Baji General Hospital.

Method: The study used a cross-sectional design for data collection method. A questionnaire was administered to 291 respondents. The data analysis was performed using a computer program and statistical analysis, namely Univariate analysis distribution (of frequency) and logistic regression.

Results: The results reveal that the determinant factors affecting the implementation of IPC are Communication $(\mathrm{P}=0.000)$, Trust and Respect $(\mathrm{P}=0.017)$, Administrative Support $(\mathrm{P}=0.000)$, Culture ( $\mathrm{P}$ $=0.000)$, Law and Regulations $(P=0.001)$, and Finance $(P=0.000)$.

Conclusion: An effective communication with other healthcare teams in the implementation of IPC leads to effective and safe healthcare services at Labuang Baji General Hospital, Makassar. Based on this reason, a policy is needed to improve the implementation of IPC in Labuang Baji General Hospital.

Keywords: health care services, Interpersonal Collaboration, individual competence.

\section{Introduction}

An efficient Interprofessional Collaboration (IPC) provides holistic services to patients in increasing the quality of healthcare and patient satisfaction as well as cost-efficient healthcare. Morley and Cashell ${ }^{1}$ state that nurses-physician relationships improve patient care quality. $\mathrm{WHO}^{2}$ and Schadewaldt et al. argue that IPC improves the quality of patient care, shortens hospital stays, reduces healthcare costs, and reduces health

\footnotetext{
Corresponding Author:

Patima Patima

Doctoral Program Science of Public Health, Universitas

Hasanuddin, Indonesia

e-mail: patima.081077@gmail.comia
}

worker's workloads and stress ${ }^{2,3}$. Besides, a study conducted by Hughes and Fitzpatrick and Gausvik et al demonstrates that IPC leads to a reduction of mortality, increased job satisfaction, and a reduction of healthcare costs 4,5 .

WHO describes the importance of IPC in decreasing total patient complications, length of hospital stay, tension and conflict among caregivers, mortality rates, cost of care, duration of treatment, and increasing patient and career satisfaction ${ }^{2}$. Meanwhile, communication is an essential thing in implementing IPC to provide health services to patients and the community. Caring without effective communication leads to guesswork and is based on stereotypes ${ }^{6}$. Communication in IPC is also a substantial effort to improve the quality of caring and patient safety ${ }^{7,8}$. 


\section{Materials and Method}

Location and Design: The researcher conducted this study at Labuang Baji General Hospital, Makassar. This study was non-experimental research with quantitative approaches, descriptive statistics and correlation, and cross-sectional study design. Population and Sample: The population in this study were all healthcare providers who provide health services to patients in the Labuang Baji Hospital treatment rooms, Makassar. The sample was 291 health workers consisting of doctors, nurses, pharmacies, and nutritionists. The sampling was performed employing proportional stratified random sampling.

Data Collection: The primary data were sparse through questionnaires and observations. The secondary data was obtained from relevant parties such as Labuang Baji General Hospital, Makassar. Data Analysis and Presentation: Data were analyzed by using computer programs and statistical tests of Univariate analysis distribution (of frequency) and logistic regression

\section{Results}

Table 1. Respondent Characteristics

\begin{tabular}{|c|c|c|}
\hline Characteristic & $\mathbf{N}$ & $\%$ \\
\hline \multicolumn{3}{|l|}{ Age (Year) } \\
\hline$<35$ & 124 & 43 \\
\hline$>=35$ & 167 & 57 \\
\hline \multicolumn{3}{|l|}{ Gender } \\
\hline Male & 89 & 31 \\
\hline Female & 202 & 69 \\
\hline \multicolumn{3}{|l|}{ Level of Education } \\
\hline Bachelor/Master & 232 & 80 \\
\hline Diploma III (three) of Health Education & 59 & 20 \\
\hline \multicolumn{3}{|l|}{ Length of Work Experience } \\
\hline$<5$ & 178 & 61 \\
\hline$>5$ & 113 & 39 \\
\hline Total & 291 & 100 \\
\hline
\end{tabular}

Table 1 depicts the most respondents aged more than 35 years old (57\%), 202 respondents (69\%) were female, the highest level of education was bachelor/master by 232 respondents $(80 \%)$, and $61 \%$ of respondents had work experiences less than five years.
Table 2. Determinant Factors of Interprofessional Collaboration (IPC)

\begin{tabular}{|l|c|l|}
\hline Determinant Factors & P & Conclusion \\
\hline Communication & 0.000 & There is a relationship \\
\hline Motivation & 0.174 & No relationship \\
\hline Trust and Respect & 0.017 & There is a relationship \\
\hline Structure & 0.052 & No relationship \\
\hline Composition & 0.315 & No relationship \\
\hline Shared Vision & 0.214 & No relationship \\
\hline Leadership & 0.025 & There is a relationship \\
\hline Administrative Support & 0.000 & There is a relationship \\
\hline Education & 0.560 & No relationship \\
\hline Culture & 0.000 & There is a relationship \\
\hline Law and Regulations & 0.001 & There is a relationship \\
\hline Finance & 0.000 & There is a relationship \\
\hline Technology & 0.450 & No relationship \\
\hline
\end{tabular}

Table 2 describes that the determinants factors associated with the implementation of IPC are Competencies with P-value 0.000, Trust and Respect with P-value 0.017, Administrative Support with P-value 0.000, Culture with P-value 0.000, Law and Regulations with P-value of 0.001, and Finance with P-value 0.000 .

\section{Discussion}

Interprofessional collaboration is when health professionals from various professions work together to provide patient-centered care. Poor communication can be the main root cause of service errors in patients. In order for collaboration between professionals to be carried out all health professionals need to know the contribution made by each profession; maintain mutual respect for each other's expertise; communicate effectively and look for continuing education training opportunities to enhance collaboration between professionals ${ }^{9}$.

The effective communication relationships for interprofessional teamwork results in positive outcomes for effective and safe healthcare services. This is consistent with the theory that communication supports high-quality, safe, effective and efficient interprofessional care in a complex health care system ${ }^{8}$. Various attempts were made as an effort to improve IPC, among other things, by implementing an integrated patient record system. IPC can optimize patient safety. 
Likewise, the efforts made by Labuang Baji General Hospital, among others, by initiating training for health workers for IPC.

Nurses and other healthcare teams are required to build an effective communication and leadership skills to work productively within interprofessional teams, establish open communication, use mutually respectful communication, and assist in decision making to promote quality patient care ${ }^{10}$. One of the core competencies for interprofessional collaborative practice is effective communication. All health workers must be able to communicate effectively with other healthcare teams to integrate safe and effective care for patients and other health workers ${ }^{11}$.

IPC within professional work environments has been recognized by nursing staff, other healthcare teams and health care professional associations as an essential determinant in improving patient safety with high quality and providing patient-centered care ${ }^{11}$. In its implementation there will be a general challenge that can be found, namely the cultural complexity of the arrangements which are socio-cultural aspects of each health profession ${ }^{12}$.

Collaboration among health professionals and effective interprofessional collaborative practices are the theme developed in hospitals for healthcare settings 11,13. Collaboration between healthcare professionals providing services to patients is an effective way to stabilize care, reduce the excessive use of the health care system, increase the delivery of health services, and reduce the cost of care ${ }^{14}$. Interprofessional teamwork is a very effective factor that can contribute to positive interprofessional collaboration practices ${ }^{15}$.

\section{Conclusion}

Based on the findings, determinant factors of the implementation of IPC are Communication $(\mathrm{P}=0.000)$, Trust and Respect $(\mathrm{P}=0.017)$, Administrative Support $(\mathrm{P}=0.000)$, Culture $(\mathrm{P}=0.000)$, Law and Regulations $(\mathrm{P}=0.001)$, and Finance $(\mathrm{P}=0.000)$.

Implication: IPC is an effective and efficient strategy to improve healthcare quality and patient health outcomes at Labuang Baji General Hospital, Makassar. IPC should, therefore, be continuously improved and developed. Further studies exploring challenges that become obstacles of physicians-nurses IPC with more accurate research instruments are needed.
Ethical Clearance: Taken from Faculty of Public Health, Universitas Hasanuddin ethical committee

Source of Funding: Self

Conflict of Interest: Nil

\section{References}

1. Morley L, Cashell A. Collaboration in Health Care. J Med Imaging Radiat Sci [Internet]. 2017;48(2):207-16. Available from: http://dx.doi. org/10.1016/j.jmir.2017.02.071

2. WHO. Human Resources for Health Framework for Action on Interprofessional Education \& Collaborative Practice [Internet]. 2010. Available from: http://www.who.int/hrh/nursing_midwifery/ en/\%0ACopies

3. Schadewaldt V, Mcinnes E, Hiller JE, Gardner A. Views and Experiences of Nurse Practitioners and Medical Practitioners with Collaborative Practice in Primary Health Care - an Integrative Review. BMC Fam Pract [Internet]. 2013;14(1):1. Available from: www.biomedcentral.com/1471-2296/14/132

4. Hughes B, Fitzpatrick JJ. Nurse-Physician Collaboration in An Acute Care Community Hospital. J Interprofesional Care [Internet]. 2010;24(6). Available from: https://doi. org/10.3109/13561820903550804

5. Gausvik C, Lautar A, Miller L, Pallerla H, Schlaudecker J. Structured Nursing Communication on Interdisciplinary Acute Care Teams Improves Perceptions of Safety, Efficiency, Understanding of Care Plan and Teamwork as Well as Job Satisfaction. J Multidiscip Healthc [Internet]. 2015;8:33-7. Available from: http://dx.doi.org/10.2147/JMDH. S72623

6. Bello O. Effective Communication in Nursing Practice : A literature Review [Internet]. 2017. Available from: https://core.ac.uk/download/ pdf/84798372.pdf

7. Dewi M, Suza E, Arruum D. The Influence of Reinforcing Nurse-Doctor Inter-professional Collaboration on Patient Safety Target at RSUP H . Adam Malik, Medan. J Nurs Heal Sci [Internet]. 2019;8(5):43-9. Available from: https://www. iosrjournals.org/iosr-jnhs/papers/vol8-issue5/ Series-8/E0805084349.pdf

8. Gordon M, Baker P, Catchpole K, Darbyshire D, Shocken D. Devising a Consensus Definition and 
Framework for Non-Technical Skills in Healthcare to Support Educational Design: A Modified Delphi study. Med Teach [Internet]. 2015;37(6). Available from: https://www.ncbi.nlm.nih.gov/ pubmed/25244065

9. AMN Healthcare Education Services. Interprofessional Collaboration [Internet]. RN.com; 2013. Available from: https://ms.rn.com/getpdf. php/1892.pdf

10. Kreps GL. Communication and Effective Interprofessional Health Care Teams. Int Arch Nurs Heal Care [Internet]. 2016;2(3):91. Available from: https://clinmedjournals.org/articles/ianhc/ international-archives-of-nursing-and-health-careianhc-2-051.pdf

11. Interprofessional Education Collaborative Expert Panel. Core Competencies for Interprofessional Collaborative Practice [Internet]. Washington D.C; 2011. Available from: https://www.aacom. org/docs/default-source/insideome/ccrpt05-10-11. pdf?sfvrsn=77937f97_2

12. Findyartini A, Kambey DR, Yusra RY, Timor AB, Khairani CD, Setyorini D, et al. Interprofessional Collaborative Practice in Primary Healthcare Settings in Indonesia: A mixed-Method Study. J Interprofessional Educ Pract [Internet]. 2019;17:100279. Available from: https://doi. org/10.1016/j.xjep.2019.100279

13. Green $\mathrm{BN}$, Johnson $\mathrm{CD}$. Interprofessional Collaboration in Research, Education, and Clinical Practice: Working Together for a Better Future.
J Chiropr Educ [Internet]. 2015;29(1):1-10. Available from: https://www.ncbi.nlm.nih.gov/ pmc/articles/PMC4360764/pdf/i1042-5055-29-11.pdf

14. Hardin L, Kilian A, Spykerman K. Competing Health Care Systems and Complex Patients: An Inter-professional Collaboration to Improve Outcomes and Reduce Health Care Costs. J Interprofessional Educ Pract [Internet]. 2017;7:510. Available from: http://dx.doi.org/10.1016/j. xjep.2017.01.002

15. Kholed SNS, Hassan NM, Ma'on SN, Hamid NZA. Teamwork and Collaboration in Healthcare: Elements of Inter-professional Teamwork. J Comput Theor Nanosci [Internet]. 2017;23(11). Available from: https://www.ingentaconnect. com/content/asp/as1/2017/00000023/00000011/ $\operatorname{art} 00081$

16. Posmaningsih, D.A., Aryasih, G.A.M., Hadi, M.C., Marwati, N.M., Mallongi, A. The influence of media booklet in behavior change of waste management in elementary school students, South Denpasar, Bali., Indian Journal of Public Health Research and Development. Volume 9, Issue 8, August 2018, Pages 1506-1511

17. Mallongi, A., Puspitasari, A., Ikhtiar, M.,Arman, Arsunan, A.A., Analysis of risk on the incidence of scabies Personal Hygiene in Boarding School Darul Arqam Gombara Makassar., Indian Journal of Public Health Research and Development., Volume 9, Issue 4, April 2018, Pages 227-231 